\title{
Nestedness analysis as a tool to identify ecological gradients
}

\author{
Werner Ulrich \\ Department of Animal Ecology, Institute of Ecology and Protection of Environment, \\ Nicolaus Copernicus University, Gagarina 9, 87-100 Toruń; Poland \\ e-mail: ulrichw@umk.pl
}

\begin{abstract}
Nestedness describes patterns of species composition within continental biotas and among isolated habitats such as islands and landscape fragments. In a nested pattern, the species composition of small assemblages is an ordered subset (a true sample) of the species composition of large assemblages. Nested subsets of species are generated by environmental and ecological gradients, such as habitat quality, carrying capacities of sites, isolation, or fragmentation, that cause ordered sequences of species extinctions and colonization. Therefore nestedness analysis can be used to identify gradients that influence species composition and richness among sites and to identify species that run counter to these gradients (idiosyncratic species). Here I review the use of nestedness analysis to identify such gradients. I also describe how to perform the analysis and which metrics and null models to use for statistical inference.
\end{abstract}

Key words: presence - absence matrix, NODF, discrepancy, idiosyncrasy, matrix temperature, species richness, null models.

\section{The basic concept}

Recently, the study of nested subset patterns in ecological presence - absence matrices has become increasingly popular (reviewed in Ulrich et al. 2009). Nestedness describes patterns of species composition within continental biotas and among isolated habitats such as islands and landscape fragments (Box 1). In a nested pattern, the species composition of small assemblages is a nested subset (a true sample) of the species composition of large assemblages (Patterson \& Atmar 1986; Patterson 1987). Nestedness analyses became popular among biogeographers after these authors proposed that nested subset patterns reflected an orderly sequence of extinctions on islands and in fragmented landscapes. Afterwards, they introduced an intuitive "matrix temperature" metric to quantify the pattern of nestedness (Atmar \& Patterson 1993, 1995).

Nested subsets of biogeographic matrices are caused by a number of ecological processes (Tab. 1). Initially nestedness analysis was seen as a tool to identify ordered sequences of extinction and colonization on true islands (Patterson 1987) and habitat islands (Patterson \& Atmar 2000). Patterson (1987) and Wright et al. (1998) linked nestedness directly to the theory of island biogeography (McArthur \& Wilson 1963). In this theory extinction and colonization are driven by two gradients, island area and island distance, and at equilibrium species richness should be ordered according to both. According to Patterson \& Atmar (2000), habitat fragmentation is expected to generate a nested pattern because fragmented landscapes are characterized by patches that differ in size and relative isolation. Patterson \& Atmar (2000) predicted that nestedness within fragmented landscapes is caused mostly by ordered extinction sequences. That means that smaller fragments selectively lose species that are habitat specialists with low abundance; these same species have a better chance of persistence in larger and/or less isolated fragments.

Blake (1991), Greve et al. (2005) and Driscoll (2008) pointed to differences in environmental tolerance as a cause of nestedness. Environmental tolerance implies a gradient 
Box 1. Four types of presence - absence matrices. Prior to analysis rows and columns of the matrix have to be ordered. Columns are ordered either according to species richness or according to some predefined environmental gradient. Rows are ordered according to species richness or, if known, according to occupation probability. In the following four examples matrices are ordered in accord to marginal totals.

In a perfectly nested matrix all occurrences are centred in the upper left and absences in the lower right margin of the matrix. Occupied and unoccupied areas can be separated by a curved isoclines has had been proposed by Atmar and Patterson (1993). Note that species occurrences are maximally aggregated that means species tend to occur together

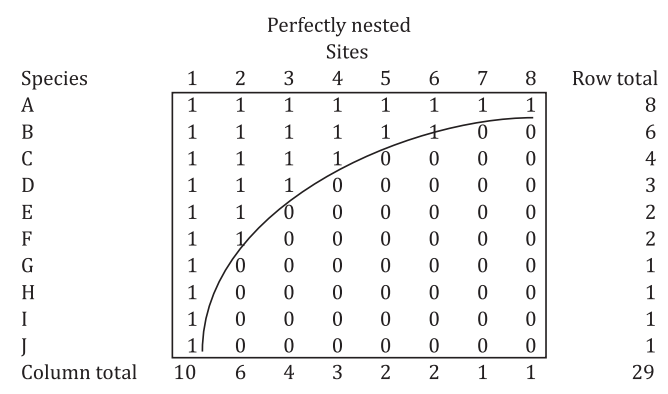

A nested matrix is less perfectly ordered and contains zeros (holes) in the area above the isoclines (bold faced) and ones (outliers) below the isoclines. In this case isoclines are constructed as two straight lines towards the matrix diagonal in that way that they separate areas with the lowest numbers of holes and outliers as proposed by Ulrich (2006) and Ulrich and Gotelli (2007). This construction is unequivocal while for curved isoclines (Atmar \& Patterson 1993, 1995) different solutions exist (Rodríguez-Gironés \& Santamaría 2006)

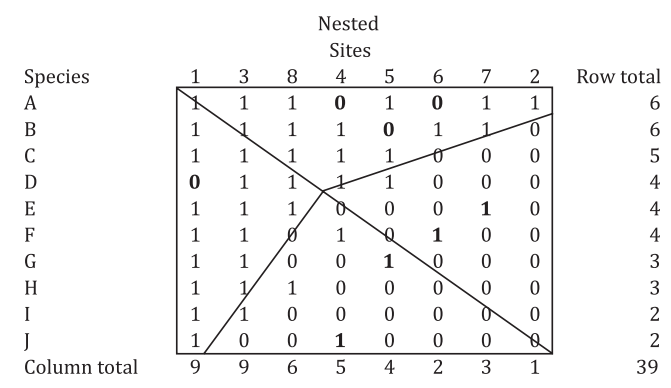

A random matrix does not significantly differ from a matrix with random occurrence at a predefined error benchmark. Random occurrence is defined with respect to a specific null hypothesis that is realized by a null model algorithm

\begin{tabular}{l|ccccccccr}
\multicolumn{7}{c}{ Sandom } \\
Species & 1 & 2 & 3 & 4 & 5 & 6 & 7 & 8 & Row total \\
A & 1 & 1 & 1 & 0 & 0 & 0 & 1 & 1 & 5 \\
B & 1 & 1 & 1 & 0 & 0 & 0 & 1 & 1 & 5 \\
C & 1 & 1 & 0 & 1 & 0 & 1 & 1 & 0 & 5 \\
D & 1 & 1 & 0 & 1 & 1 & 1 & 0 & 0 & 5 \\
E & 0 & 1 & 1 & 0 & 1 & 0 & 0 & 1 & 4 \\
F & 1 & 1 & 0 & 1 & 1 & 0 & 0 & 0 & 4 \\
G & 1 & 1 & 1 & 1 & 0 & 0 & 0 & 0 & 4 \\
H & 1 & 0 & 1 & 1 & 0 & 1 & 0 & 0 & 4 \\
I & 0 & 0 & 0 & 0 & 1 & 0 & 1 & 1 & 3 \\
J & 1 & 0 & 0 & 0 & 0 & 1 & 0 & 0 & 2 \\
Column total & 8 & 7 & 5 & 5 & 4 & 4 & 4 & 4 & 41
\end{tabular}

Anti-nestedness (Almeida-Neto et al. 2007) refers to the opposite of nestedness. Species occurrences are even less nested that expected by the null model. This is only possible if species co-occurrences are highly segregated. A convenient measure for species segregation is the number of checkerboards. Checkerboards are $2 \times 2$ submatrices of reciprocal species exclusion $\{(1,0),(0,1)\}$ (within rectangles). The higher the number of checkerboards is, the more segregated is a matrix

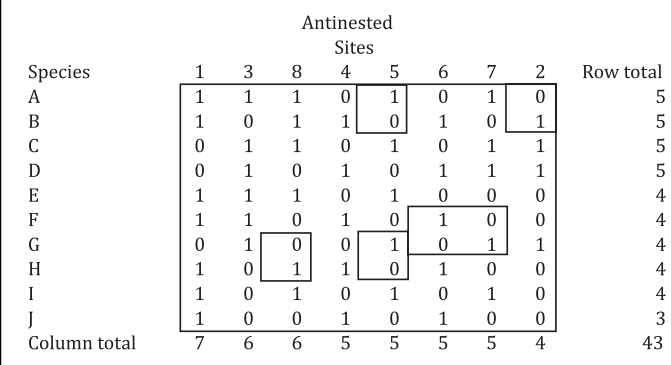


Table 1. Causes of nested subset patterns in metacommunities (modified from Ulrich et al. 2009)

\begin{tabular}{|c|c|c|c|}
\hline \multirow{2}{*}{ Mechanism } & \multicolumn{2}{|c|}{ Assumption/Precondition } & \multirow{2}{*}{ Predictions } \\
\hline & gradient of site properties & gradient of species properties & \\
\hline Passive sampling & $\begin{array}{l}\text { - barrying capacities of } \\
\text { sites }\end{array}$ & - regional abundance & - regional abundance predicts occupancy \\
\hline Selective colonization & - isolation & - dispersal ability & $\begin{array}{l}\text { - selective occupancy of sites according to } \\
\text { isolation }\end{array}$ \\
\hline Selective extinction & $\begin{array}{l}\text { - carrying capacities of } \\
\text { sites }\end{array}$ & $\begin{array}{l}\text { - extinction susceptibility } \\
\text { (faunal relaxation) }\end{array}$ & $\begin{array}{l}\text { - selective occupancy of sites according to } \\
\text { area of sites }\end{array}$ \\
\hline Nested habitats & - habitat heterogeneity & - degrees of specialization & $\begin{array}{l}\text { - higher proportion of generalist species in } \\
\text { smaller and/or resource poor patches }\end{array}$ \\
\hline $\begin{array}{l}\text { Selective environ- } \\
\text { mental tolerances }\end{array}$ & - environmental harshness & - environmental tolerances & $\begin{array}{l}\text { - selective occupancy of sites according to } \\
\text { tolerance to environmental stress }\end{array}$ \\
\hline Habitat quality & - environmental harshness & - & $\begin{array}{l}\text { - site occupancy in accordance to the ideal } \\
\text { free distribution model. }\end{array}$ \\
\hline
\end{tabular}

in ecological specialization (niche wide) and species richness should increase with the number of generalist species. Closely related to environmental tolerance is species selection according to habitat quality, often termed habitat filtering (Webb et al. 2002). Under habitat filtering species should occupy sites according to species specific traits. As a result, an ideal free distribution (Fretwell \& Lucas 1970) at the species level appears (Hylander et al. 2005; Bloch et al. 2007).

The most common cause of nestedness is the so called passive sampling. Passive sampling needs to gradients. First species do not have equal probabilities to colonize a site. Due to a simple mass effect, regionally abundant species have a much higher chance to occupy sites than regionally rare species. Second, if sites differ in carrying capacities larger sites will get more individuals and therefore more species. Both processes result in a nested subset pattern (Ulrich \& Gotelli 2007a; Ulrich et al. 2009). Lastly, disturbance can produce a nested subset pattern if an ordered sequence of extinction occurs along the gradient of disturbance (Worthen et al. 1998; Fernández-Juricic 2002; Bloch et al. 2007).

A common theme is that the proximate causes for nestedness are ecological gradients (Ulrich et al. 2009) along which species richness is ordered. Hence nestedness analysis might be a tool to identify gradients that structure ecological communities (Lomolino 1996; Patterson \& Atmar 2000; Leibold \& Mikkelson 2002; Leibold et al. 2004; Ulrich et al. 2009).

\section{Quantifying nestedness}

\subsection{Metrics}

To date more than ten different metrics have been proposed to quantify the degree of nestedness within ecological presence - absence matrices (reviewed in Wright et al. 1998 and Ulrich et al. 2009). However, recent research showed that most of them have undesired statistical properties concerning type I and II error probabilities (Ulrich \& Gotelli 2007a, b; Almeida-Neto et al. 2008; Ulrich et al. 2009). Further, any metric must have four basic properties. 1. It must be invariant to matrix size and shape. 2. It must be invariant to matrix fill. 3. Because it is arbitrary to put sites in columns or rows, any metric must be invariant to matrix transpose. 4 . There is a priori no reason to treat presences and absences differentially (Ulrich et al. 2009). Hence any metric must be invariant to occurrence inversion (ones to zeros and vice versa).

Recent research (Ulrich \& Gotelli 2007a, b; Almeida-Neto et al. 2008) pointed to three metrics to have the desired statistical properties. The discrepancy metric BR (Brualdi \& Sanderson 1999; Brualdi \& Shen 1999) an it's transpose invariant modification Ulrich (2006) counts of the minimum number of discrepancies (absences or presence) for rows and columns that must be erased to produce a perfectly nested matrix (Fig 1). Almeida-Neto et al. (2008) introduced the metric NODF based on standardized differences in row and column fills and paired matching of occurrences. An appealing feature of NODF is that it 


\begin{tabular}{|c|c|c|c|c|c|c|c|c|c|}
\hline \multicolumn{10}{|c|}{ Sites } \\
\hline Species & 1 & 3 & 8 & 4 & 5 & 6 & 7 & 2 & Row total \\
\hline A & 1 & 1 & 1 & $\uparrow 0$ & $<1$ & 10 & -1 & 1 & 6 \\
\hline B & 1 & 1 & 1 & 1 & 个O & 1 & 1 & 0 & 6 \\
\hline C & 1 & 1 & 1 & 1 & 1 & 0 & 10 & 0 & 5 \\
\hline D & 0 & 1 & 1 & 1 & -1 & 0 & 0 & 0 & 4 \\
\hline E & $\Uparrow$ & 1 & 1 & $0<$ & $\theta$ & $\theta$ & -1 & 0 & 4 \\
\hline $\mathrm{F}$ & 1 & 1 & 0 & & 0 & 1 & 0 & 0 & 4 \\
\hline G & 1 & 1 & 0 & 0 & -1 & 0 & 0 & 0 & 3 \\
\hline $\mathrm{H}$ & 1 & 1 & 1 & 0 & 0 & 0 & 0 & 0 & 3 \\
\hline I & 1 & 1 & 0 & 0 & 0 & 0 & 0 & 0 & 2 \\
\hline J & 1 & 0 & $<0$ & -1 & 0 & 0 & 0 & 0 & 2 \\
\hline Column total & 9 & 9 & 6 & 5 & 4 & 2 & 3 & 1 & 39 \\
\hline
\end{tabular}

Figure 1. Discrepancy measures the number of shifts of one's into zeros to get a perfectly nested matrix. The minimum number of shifts within rows and column is the metric. In this case both numbers equal $\mathrm{D}=7$

decomposes total nestedness into a sum of the nestedness introduced by columns and by rows. In other words they showed that nestedness can be seen as the sum of row and column wide aggregation of species occurrences. So far, most authors used the temperature metric $T$ of Atmar and Patternson (1993). $T$ is a normalized sum of squared relative distances of absences above and presences below the hypothetical isocline that separates occupied from unoccupied areas in a perfectly nested matrix (Fig. 2). Contrary to the other two recommended metrics $T$ correlates positively with matrix size (Ulrich \& Gotelli 2007a; Ulrich et al. 2009). All these metrics are incorporated in the widely used Nestedness software (Ulrich 2006).

\subsection{Statistical inference}

Nestedness analysis needs a prior sorting of the matrix. Traditionally matrices have been sorted according to row and column totals. However, a sorting of sites to any gradient that might influence the degree of nestedness seems appropriate to infer the relative strength of this gradient (Lomolino 1996).

Any statistical inference needs two contrasting hypothesis. With respect to nestedness analysis our metrics provide $\mathrm{H}_{1}$, the hypothesis about a certain degree of nestedness within the matrix. $\mathrm{H}_{0}$, the hypothesis that this value does not differ from what is expected by chance is provided by an additional hypothesis on what is randomness in ecological communities. This question has been highly controversial (Connor \& Simberloff 1979; Diamond \& Gilpin 1982; Gotelli \& Graves 1996) but recent research clarified some basic requirements proper null hypotheses have to fulfil (Gotelli \& McGill 2006; Ulrich \& Gotelli 2007a, b; Arita et al. 2008). Table 3 shows the recommended models.

\begin{tabular}{|c|c|c|c|c|c|}
\hline \multicolumn{6}{|c|}{ Sites } \\
\hline Species & $\begin{array}{lll}1 & 3 & 8\end{array}$ & $4 \quad 5$ & 67 & 2 & Row total \\
\hline A & 111 & $\begin{array}{ll}0 & 1\end{array}$ & $\begin{array}{ll}0 & 1\end{array}$ & 1 & 6 \\
\hline B & $1 \backslash 1 \quad 1$ & $\begin{array}{ll}0 & 0\end{array}$ & 11 & & 5 \\
\hline C & $1 \bigwedge_{1}$ & & $\theta 0$ & 0 & 5 \\
\hline D & 012 & & $0 \quad$ & & 4 \\
\hline E & & & $0<1$ & 0 & 4 \\
\hline $\mathrm{F}$ & 10 & $1 \emptyset$ & 10 & 0 & 4 \\
\hline G & $11 / 0$ & $\begin{array}{ll}0 & 1\end{array}$ & 01 & & 4 \\
\hline $\mathrm{H}$ & $11 / 1$ & $\begin{array}{ll}0 & 0\end{array}$ & $\partial 0$ & & 3 \\
\hline I & $1 / 0$ & 00 & 12 & & 3 \\
\hline$J$ & $1 / 0 \quad 0$ & 10 & 10 & $Q$ & 3 \\
\hline Column total & $\begin{array}{lll}9 & 9 & 6\end{array}$ & 44 & $\begin{array}{ll}44 \\
\end{array}$ & $\overrightarrow{1}$ & 41 \\
\hline
\end{tabular}

Figure 2. Matrix temperature is the normalized sum of squared distances $d$ of holes and outliers from the isoclines along the matix diagonals

Null models can be ordered respective to their type I error probabilities from most liberal to conservative. Because occupancy probabilities differ among species liberal null models that do not constrain marginal totals too often point to non-randomness due to the effect of passive sampling. If the probabilities of occupancy are equal among sites (if they have similar carrying capacities) a model that constraints column totals only might be appropriate. Column totals, in turn should generally be fixed because species abundances of the meta-community necessarily differ.

A matrix is always a sample from a larger meta-community. Therefore, unseen species pose a problem. Without knowledge about the regional abundance distribution any null model operates only on this sample. Hence, it doesn't recover the whole null space and might give biased variance estimates. Another argument that speaks against the use of unconstrained null models is the fact that liberal null models are prone to give similar distributions of occurrences in larger matrices and therefore lowered variances due to statistical averaging (Ulrich unpubl.). In this respect restrictive models like the fixed - fixed model that constraints the null space to observed marginal totals, were shown to perform better than less restrictive models (Gotelli 2000; Ulrich \& Gotelli 2007a, b). Restrictive models account also at least in part for passive sampling (Ulrich et al. 2009). Hence a mixed use of a liberal and a restrictive model might be able to disentangle ecological and sampling effects in nestedness analysis.

There are now more and more data on regional species richness and abundances available. In this situation the best way of constructing random matrices is either resampling from the metacommunity or, if possible, additional neutral modelling (Hubbell 2001) that incorporates dispersal and 
Table 2. Recommended nestedness metrics (modified from Ulrich et al. 2009)

\begin{tabular}{|l|l|l|l|}
\hline \multicolumn{1}{|c|}{$\begin{array}{c}\text { Nestedness } \\
\text { metric }\end{array}$} & \multicolumn{1}{|c|}{ Author(s) } & \multicolumn{1}{c|}{$\begin{array}{c}\text { Aim } \\
\text { To quantify whether a metacommunity: }\end{array}$} & \multicolumn{1}{c|}{ Description } \\
\hline $\begin{array}{l}\text { BR (discrepancy } \\
\text { measure) }\end{array}$ & $\begin{array}{l}\text { Brualdi \& } \\
\text { Sanderson (1999) }\end{array}$ & $\begin{array}{l}\text { - deviates from a nested pattern by means } \\
\text { of minimum number of replacements of } \\
\text { presences to produce a new nested matrix }\end{array}$ & $\begin{array}{l}\text { - counts of the minimum number of } \\
\text { discrepancies (absences or presence) for } \\
\text { rows and columns that must be erased to } \\
\text { produce a perfectly nested matrix }\end{array}$ \\
\hline $\begin{array}{l}\text { T (matrix } \\
\text { temperature) }\end{array}$ & $\begin{array}{l}\text { Atmar \& } \\
\text { Patterson (1993) }\end{array}$ & $\begin{array}{l}\text { - deviates from a nested pattern due to } \\
\text { unexpected extinctions and colonizations, } \\
\text { respectively, in more and less } \\
\text { "hospitable" sites }\end{array}$ & $\begin{array}{l}\text { - a normalized sum of squared relative } \\
\text { distances of absences above and } \\
\text { presences below the hypothetical isocline } \\
\text { that separates occupied from unoccupied } \\
\text { areas in a perfectly nested matrix }\end{array}$ \\
\hline $\begin{array}{l}\text { NODF } \\
\text { (nestedness } \\
\text { measure based } \\
\text { on overlap and } \\
\text { decreasing fills) }\end{array}$ & al. (2008) & $\begin{array}{l}\text { Almeida-Neto et } \\
\text { to quantify independently (1) whether } \\
\text { depauperate assemblages constitute } \\
\text { subsets of progressively richer ones and } \\
\text { (2) whether less frequent species are } \\
\text { found in subsets of the sites where the } \\
\text { most widespread occur }\end{array}$ & $\begin{array}{l}\text { - the percentage of occurrences in right } \\
\text { columns and species in inferior rows } \\
\text { which overlap, respectively, with those } \\
\text { found in left columns and upper rows } \\
\text { with higher marginal totals for all pairs of } \\
\text { columns and of rows }\end{array}$ \\
\hline
\end{tabular}

Table 3. Recommended null models used to infer expected nestedness (species in rows, sites in columns) (modified from Ulrich et al. 208)

\begin{tabular}{|l|l|l|l|l|}
\hline \multicolumn{1}{|c|}{ Name } & $\begin{array}{l}\text { Other names used in } \\
\text { the literature }\end{array}$ & \multicolumn{1}{|c|}{ Row constraint } & Column constraint & \multicolumn{1}{|c|}{ Author(s) } \\
\hline Fixed-equiprobable & SIM2, R0, Random0 & fixed & equiprobable & $\begin{array}{l}\text { Patterson \& Atmar (1986), Gotelli } \\
(2000)\end{array}$ \\
\hline Equiprobable-fixed & SIM3 & equiprobable & fixed & Gotelli (2000) \\
\hline Fixed-fixed & SIM9 & fixed & fixed & $\begin{array}{l}\text { Connor \& Simberloff (1979), Diamond } \\
\text { \& Gilpin (1982), Gotelli (2000) }\end{array}$ \\
\hline Proportional & R $_{\text {ecol }}$ & $\begin{array}{l}\text { proportional to species } \\
\text { relative abundances }\end{array}$ & $\begin{array}{l}\text { proportional to } \\
\text { carrying capacities }\end{array}$ & Moore \& Swihart (2007) \\
\hline Neutral modelling & Ecological drift & none & none & Hubbell (2001) \\
\hline
\end{tabular}

Table 4. Observed NODF scores of 71 carabid species occurrences on 17 lake islands and mainland sites of the Mazurian lake Mamry. Prior to analysis rows were sorted to species richness and columns to species richness or environmental variables. Three PCA scores obtained for eight environmental variables explained $80 \%$ of total variance. PCA1 loaded high with soil humidity, organic matter content and mean distances from other islands, PCA2 loaded high with temperature and soil acidity, and PCA3 was mainly influenced by soil dispersion. Expected scores and the respective confidence limits were obtained from 100 random matrices generated with the conservative fixed - fixed null model (Tab. 3) (data from Ulrich \& Zalewski 2006; Zalewski \& Ulrich 2009)

\begin{tabular}{|l|c|c|c|c|c|}
\hline Sorted according to & Observed NODF & Expected NODF & Lower 95\%CL & Upper 95\%CL & P(H $\left.\mathrm{H}_{0}\right)$ \\
\hline Richness & 49.6 & 51.4 & 49.4 & 52.7 & n.s. \\
\hline Area & 49.1 & 51 & 49.2 & 52.1 & 0.05 \\
\hline PCA1 & 48.5 & 50.5 & 49.1 & 51.8 & $<0.01$ \\
\hline PCA2 & 48.2 & 50 & 48.7 & 50.9 & $<0.01$ \\
\hline PCA3 & 48.1 & 50.1 & 48.7 & 51.2 & $<0.01$ \\
\hline
\end{tabular}




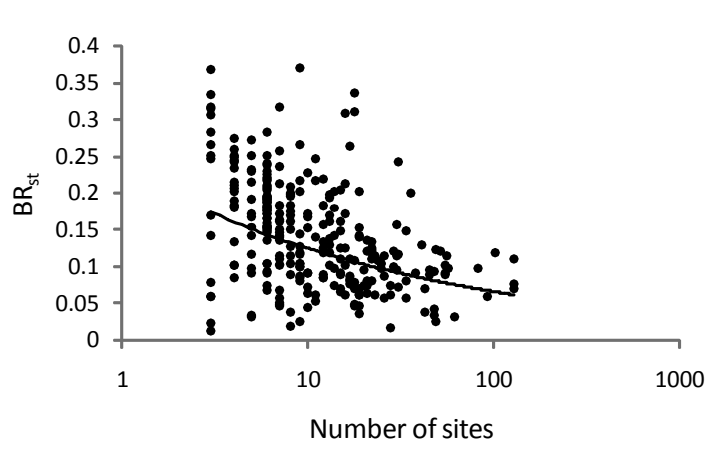

Figure 3. Standardized $\mathrm{BR}$ scores $\left(\mathrm{BR}_{\mathrm{st}}=\mathrm{BR} /\right.$ matrix fill $)$ of 288 presence - absence matrices decrease with the number of sites under study. Data from Atmar and Patterson (1995). $\mathrm{R}^{2}=0.14 ; \mathrm{P}\left(\mathrm{H}_{0}\right)<0.001$

local species turnover (Moore \& Swihart 2007; Ulrich \& Zalewski 2007; Driscoll 2008). Because null distributions are frequently skewed, significance levels of nestedness scores should always be taken from the confidence limits of the null distribution and not from the standard normal distribution. Again, the common software incorporates the recommended null algorithms, together with additional analyses of null distributions and confidence limits (Ulrich 2006).

\section{Gradient analysis}

Nestedness analyses should be accompanied by appropriate gradient analyses (Leibold \& Mikkelson 2002). An ordering of sites according to one-dimensional environmental or taxon specific gradients should result in different degrees of nestedness with respect to an ordering according to species richness and to randomized matrices and allow for an identification of the strongest gradient that causes the ordered occurrence of species (Lomolino 1996; Ulrich et al. 2009).

The technique is best explained with an example. Table 4 shows NODF nestedness scores obtained from a matrix of 71 ground beetles species trapped on 15 lake islands and two mainland sites of the Mazurian lake Mamry (Northern Poland) (Ulrich \& Zalewski 2006). Prior to nestedness analysis I performed a principal component analysis to reduce eight available environmental correlates into three significant (Eigenvalues $>1.0$ ) factors. The first factor (PCA1) loaded high with soil humidity, organic matter content and mean distances from other islands, PCA2 loaded high with temperature and soil acidity, and PCA3 was mainly influenced by soil permeability. A matrix sorted by marginal totals was not significantly nested. A weak signal of species segregation appeared after sorting according to island area. However, a sorting according all three PCA axes resulted in a strong signal of anti-nestedness (Tab. 4). In other words species occurrences along these three axes were strongly segregated. This pattern did not appear in simple regression analysis of total species richness against area and PCA axes (not shown). The above result points to competitive exclusion and segregated niche spaces along the environmental gradients defined by the PCA axes.

Another application of nestedness scores refers to multiple matrices. More and more large scale biogeography data are available, for instance the well known Atmar and Patterson (1995) set. For such environmental data nestedness scores can be correlated to environmental scores, for instance latitude, temperature, evapotranspiration, soil properties, or regional species richness. Most often rank order correlations are applied. As an example, I calculated the standardized BR score $(=\mathrm{BR} /$ matrix fill) (Greve \& Chown 2006) for 288 biogeographic matrices of the Atmar-Patterson set and compared the observed scores with the number of sites in the matrix (Fig. 3). A highly significant negative correlation appeared that seems quite plausible. Many sites are necessarily spread over a larger region. The higher habitat heterogeneity at these scales should weaken the effect of any environmental gradient that might influence community structure at smaller scales.

Nestedness is linked to the common species - area and isolation - diversity relationships (MacArthur \& Wilson 1963). A sorting of sites according to patch area and the degree of isolation can be used to infer whether a system is colonization or extinction driven (Bruun \& Moen 2003). If the matrix sorted by the area of sites is nested but the matrix sorted by the degree of isolation is not, the system should be extinction-driven because colonization does not seem to be sufficiently strong to generate nestedness.

\section{Idiosyncrasy}

Atmar and Patterson (1993) termed species that decrease the degree of nestedness "idiosyncratic" (Box 1). Idiosyncratic species are those with comparably high numbers of holes and outliers (see Box 1) and run counter to the ecological and geographical gradients that cause the nested subset patterns. Important is that idiosyncratic species can even be detected in matrices without distinct nestedness. An interesting example of nestedness analysis contains Soininen (2008). He showed that idiosyncratic diatom species occurred regionally more widespread than "normal" species, a pattern that surely deserves attention (Ulrich et al. 2009). Moreover, assemblages dominated by idiosyncratic species appeared to have rather high local species turnover (Soininen 2008). This finding is consistent with the selective extinction hypothesis for nestedness (Patterson 1990). 


\section{Conclusion}

Nestedness analysis has proven to be an important tool for inferring ecological patterns. It allows for an identification of the strongest gradient that influences an ordered site occupation of species. Furthermore, nestedness analysis can identify 'deviating' species that run counter to those gradients. However, nestedness analysis has to be done with care. Metric and null model choice might heavily influence the results (Wright et al. 1998; Ulrich \& Gotelli 2007a; Ulrich et al. 2009). As a rule of thumb, a conservative null model and a metric that is independent on basic matrix properties like matrix size and fill should be used.

\section{Acknowledgments}

I thank Mário Almeida-Neto and Nick Gotelli for the many discussions around the concept of nestedness. Miss Hazel Pearson kindly improved my English. This work was in part supported by a grant from the Polish Committee for Scientific Research (KBN, 3F04F03422).

\section{References}

Almeida-Neto M., Guimarães P. R. Jr. \& Lewinsohn T. M., 2007, On nestedness analyses: rethinking matrix temperature and anti-nestedness, Oikos 116: 716-722.

Almeida-Neto M., Guimarães P., Guimarães P. R. Jr., Loyola R. D. \& Ulrich W., 2008, A consistent metric for nestedness analysis in ecological systems: reconciling concept and quantification, Oikos: 117: 1227-1239.

Arita H. T., Christen J. A., Rodríguez P. \& Soberón N., 2008 , Species diversity and distribution in presenceabsence matrices: mathematical relationships and biological implications, Am. Nat. 172: 519-532.

Atmar W. \& Patterson B. D, 1993, The measure of order and disorder in the distribution of species in fragmented habitat, Oecologia 96: 373-382.

Atmar W. \& Patterson B. D., 1995, The nestedness temperature calculator: a Visual Basic program, including 294 presence-absence matrices, AICS Research, Univ. Park, NM and Field Museum, Chicago, http://aics-research. com/nestedness/tempcalc.html, retrived: 10.06.2009.

Blake J. G., 1991, Nested subsets and the distribution of birds on isolated woodlots, Cons. Biol. 5: 58-66.

Bloch C. P., Higgins C. L. \& Willig M. W., 2007, Effects of large-scale disturbance on metacommunity structure of terrestrial gastropods: temporal trends in nestedness, Oikos 116: 395-406.

Brualdi R. A. \& Sanderson J. G., 1999, Nested species subsets, gaps, and discrepancy, Oecologia 119: 256-264.
Brualdi R. A. \& Shen J., 1999. Discrepancy of Matrices of Zeros and Ones. Electr. J. Comb. 6: R 15.

Bruun H. H. \& Moen J., 2003, Nested communities of alpine plants on isolated mountains: relative importance of colonization and extinction, J. Biogeogr. 30: 297-303.

Connor E. H. \& Simberloff D., 1979, The assembly of species communities: chance or competition?, Ecology 60: 1132-1140.

Diamond J. M. \& Gilpin M. E., 1982, Examination of the "null" model of Connor and Simberloff for species cooccurrence on islands, Oecologia 52: 64-74

Driscoll D. A., 2008, The frequency of metapopulations, metacommunities and nestedness in a fragmented landscape, Oikos 117: 297-309.

Fernández-Juricic E., 2002, Can human disturbance promote nestedness? A case study with birds in an urban fragmented landscape, Oecologia 131: 269-278.

Fretwell S. D. \& Lucas H. J., 1970, Ideal free distribution. Acta Biotheor. 19: 16-21.

Gotelli N. J., 2000, Null model analysis of species co-occurrence patterns, Ecology 81: 2606-2621.

Gotelli N. J. \& Graves G. R., 1996, Null models in ecology, Smith. Inst. Press, Washington D.C.

Gotelli N. J. \& McGill B. J., 2006, Null versus neutral models: what's the difference?, Ecography 29: 793800.

Greve M. \& Chown S. L., 2006, Endemicity biases nestedness metrics: a demonstration, explanation and solution, Ecography 29: 347-356.

Greve M., Gremmen N. J. M., Gaston K. J. \& Chown S. L., 2005, Nestedness of Southern Ocean island biotas: ecological perspectives on a biological conundrum, J. Biogeogr. 32: 155-168.

Hubbell S. P., 2001, The unified theory of biogeography and biodiversity, University Press, Princeton.

Hylander K., Nielson C., Jonsson B. G. \& Göthner T., 2005, Differences in habitat quality explain nestedness in a land snail meta-community, Oikos 108: 351-361.

Leibold M. A. \& Mikkelson G. M., 2002, Coherence, species turnover, and boundary clumping: elements of meta-community structure, Oikos 97: 237-250.

Leibold M. A. et al., 2004, The metacommunity concept: a framework for multiscale community ecology, Ecol. Lett. 7: 601-613.

Lomolino M. V., 1996, Investigating causality of nestedness of insular communities: selective immigration or extinction, J. Biogeogr. 23: 699-703.

MacArthur R. H. \& Wilson E. O., 1963, An equilibrium theory of insular zoogeography, Evolution 17: 373387.

Moore J. E. \& Swihart R. K., 2007, Toward ecologically explicit null models of nestedness, Oecologia 152: 763-777. 
Patterson B. D., 1987, The principle of nested subsets and its implications for biological conservation, Conserv. Biol. 1: 323-334.

Patterson B. D., 1990, On the temporal development of nested subset patterns of species composition, Oikos 59: 330-342.

Patterson B. D. \& Atmar W., 1986, Nested subsets and the structure of insular mammalian faunas and archipelagos, Biol. J. Linn. Soc. 28: 65-82.

Patterson B. D. \& Atmar W., 2000, Analyzing species composition in fragments, Bonner Zoologische Monographien 46.

Rodríguez-Gironés M. A. \& Santamaría L., 2006, A new algorithm to calculate the nestedness temperature of presence-absence matrices, J. Biogeogr. 33: 924-935.

Soininen J., 2008, The ecological characteristics of idiosyncratic and nested diatoms, Protist 159: 65-72.

Ulrich W., 2006, Nestedness - a FORTRAN program for calculating ecological matrix temperatures, www.uni. torun.pl/ ulrichw.

Ulrich W. \& Gotelli N. J., 2007a, Null model analysis of species nestedness patterns, Ecology 88: 1824-1831.
Ulrich W. \& Gotelli N. J., 2007b, Disentangling community patterns of nestedness and species co-occurrence, Oikos 116: 2053-2061.

Ulrich W. \& Zalewski M., 2006, Abundance and co-occurrence patterns of core and satellite species of ground beetles on small lake islands, Oikos 114: 338-348

Ulrich W. \& Zalewski M., 2007, Are ground beetles neutral?, Basic Appl. Ecol. 8: 411-420.

Ulrich W., Almeida-Neto M. \& Gotelli N., 2009, A consumer's guide to nestedness analysis, Oikos 118: 3-17.

Webb C. O., Ackerly D. D., McPeek M. A. \& Donoghue K. L., 2002, Phylogenies and community ecology, Ann. Rev. Ecol. Syst. 33: 475-505.

Worthen W. B., Jones, M. T. \& Jetton R. M., 1998, Community structure and environmental stress: desiccation promotes nestedness in mycophagous fly communities, Oikos 81: 45-54.

Wright D. H., Patterson B. D., Mikkelson G. M., Cutler A. \& Atmar W., 1998, A comparative analysis of nested subset patterns of species composition, Oecologia 113: 1-2

Zalewski M. \& Ulrich W. 2009. Island colonization of Carabidae: neutrality or habitat choice, Israel J. Ecol., in press. 